\title{
STORE TIME OF PERMETHRIN IN THE TRUCK-MOUNTED ULV SPRAY TANKS CAUSED DEGRADATION IN THE CONCENTRATIONS
}

\author{
RUI-DE XUE1, MAIA TSIKOLIA2, WHITNEY A. QUALLS3, \\ AND ULRICH BERNIER2 \\ 'Anastasia Mosquito Control District, 120 EOC Drive, \\ St. Augustine, FL, 32092.
}

${ }^{2}$ USDAVARS, Center for Medical, Agriculture, and Veterinary Entomology, Gainesville, FL 32608

\author{
${ }^{3}$ Texas Department of State Health Service/ Zoonosis Control Branch, \\ Austin, TX 78714
}

\section{Guest Editor: Caroline Efstathion}

\begin{abstract}
Permethrin is one of the few active ingredients found in commercial adulticides available for adult mosquito control. The permethrin concentrations in the adulticide Aqualuer 20-20 formulation stored in the 21 ultra-lowvolume (ULV) truck-mounted spray tanks after 4, 6, and 8 months were sampled and analyzed by gas chromatography mass spectroscopy (GC-MS). Additionally, the permethrin stored in a mixing pump and a stock container were sampled and analyzed by GC-MS. The results showed that $46 \%, 42 \%$, and $82 \%$, permethrin in Aqualuer 20-20 were decomposed in the ULV spray tanks at 4-, 6-, and 8 months-storage, respectively. For the mixing pump, 17\% of the permethrin in the Aqualuer 20-20 were decomposed. The storage time of permethrin in ULV spray tanks resulted in the degradation in the concentrations of permethrin after more 4 months, compared with the concentration in stock control. The degradation of permethrin in ULV spray tanks may directly impact the control efficacy for adult mosquitoes and result in an economic loss.
\end{abstract}

Key Words: permethrin, decomposition, adulticide, Aqualuer, storage time, gas chromatography mass spectroscopy (GC-MS), analysis

Permethrin is the active ingredient of several commercial mosquito adulticide products (Amoo et al. 2012; Brown \& Xue 2011). Xue et al. 2008 found that about $50 \%$ permethrin in the adulticide previously used by the mosquito control program decomposed in the truck-mounted ultra-lowvolume (ULV) spray tanks when mixed with water and stored over the winter for the upcoming mosquito season. However, we do not know whether time of storage impacts the degradation of permethrin after mixing with water. The purpose of the study was to examine whether time, 4,6 , and 8 months, of storage of the mixed permethrin product
Aqualuer 20-20 (active ingredient is $20.6 \%$ permethrin, AllPro Inc., P. O. Box 585, St. Joseph, MO 64502) in the truck-mounted ULV spray tanks and in the mixing pump impacts the permethrin concentration.

The assessment was conducted by taking permethrin samples from each spray tank (total 21 trucks) and one mixing pump. The sampling process included agitating the mixture for 5 mins with a handled agitator before taking the sample from each tank. A 10- mL sample from the middle of the spray tank was taken with a $10-\mathrm{mL}$ disposable plastic pipette. The samples were immediately placed into $20 \mathrm{~mL}$ glass bottles and 
labeled according to the truck tank numbers and date. The water-mixed solution from the mixing pump was drained to a plastic bucket and a $10 \mathrm{~mL}$ solution was sampled from the bucket after agitation. Control samples were obtained from the stock container following the agitation after circulation and dilution 1:10 Aqualuer 20-20 and well water. All samples were sealed, stored with coolants, and transferred for analysis to the United States Department of Agriculture (USDA), Center for Medical, Agricultural, and Veterinary Entomology (CMAVE), Gainesville, FL.

All samples were analyzed for permethrin residue by using a gas-chromatography mass spectroscopy (GC-MS). Permethrin $(98.0 \%$ purity) was purchased from Chem Service, Inc., West Chester, PA; Internal standard (ISTD) dibutyl phthalate (99\% purity) from Supelco, Ballefonte, PA. Quechers SPE Resprep $15 \mathrm{~mL}$ tubes with $900 \mathrm{mg} \mathrm{MgSO}$ 4, $300 \mathrm{mg}$ PSA (primary and secondary amine exchange material), and 150 mg GCB (graphitized carbon black) were purchased from Restek, Ballefonte, PA. Acetone (HPLC grade) was obtained from Sigma-Aldrich, Saint Louis, USA.

Pyrex conical-bottom $15 \mathrm{ml}$ disposable glass centrifuge tubes (Cole-Parmer North America, 625 East Bunker Court, Vernon Hills, IL 60061, USA) were used for sample preparation. Sample solutions were transferred using Fisher brand disposable borosilicate glass Pasteur pipets (purchased from Sigma-Aldrich, Saint Louis, USA), 9-inch pipets were used to transfer the sample solutions and 5.75-inch pipets to collect concentrated solution through cotton filter into the $1 \mathrm{~mL}$ Pyrex cylindrical volumetric flask with stopper \#8 (Fisher Scientific, Waltham, MA, USA). Five- and eight $\mathrm{mL}$ amber bottles were used to store stock and internal standard solutions. For sonication, shaking, vortexing and centrifuging the following instruments were used: Model FS140 Sonic Bath, Genie 2 Vortex mixer 12-812 and Centrifuge Model 228 (all from Fisher Scientific, Waltham, MA, USA), Excella E2 Platform shaker (New Brunswick Scientific, Enfield, CT, USA).
Three stock standard solutions were prepared as follows: Three $20 \mathrm{~mL}$ blank samples were transferred into Quencher's $15 \mathrm{ml}$ centrifuge tubes, each spiked with $2.5 \mathrm{mg}$ permethrin, added acetone up to 6 $\mathrm{mL}$, vortexed (30 sec), sonicated (30 min), shake (15 min, $300 \mathrm{rpm})$, centrifuged (15 $\min , 600 \mathrm{rpm}$ ) and transferred into glass $15 \mathrm{ml}$ conic centrifuge tube. This procedure was repeated two more times with sonicating 15- and $5 \mathrm{~min}$, respectively. Then the collected sample solution in glass conic centrifuge tube was concentrated to $0.5 \mathrm{ml}$. The concentrated solution was transferred into $1 \mathrm{~mL}$ volumetric flask through $0.5 \mathrm{mg}$ cotton filter (placed in the 5.75-inch Pasteur pipet). The centrifuge tube was washed twice with acetone and the solution was added to a volumetric flask. The solution in volumetric flask was filled up to $1 \mathrm{~mL}$ with acetone. Then, each recovered standard stock solution was diluted accordingly to yield solutions of five different concentrations for each range: 1st: $20-100 \mathrm{ng} / \mathrm{mL}(20,50,70,80$ and 100 $\mathrm{ng} / \mathrm{mL})$, 2nd: 200-500 ng/mL (200, 250, 300,400 and $500 \mathrm{ng} / \mathrm{mL}$ ) and 3rd: 600$1,000 \mathrm{ng} / \mathrm{mL}(600,700,800,900$ and 1000 $\mathrm{ng} / \mathrm{mL}$ ). A $10 \mathrm{~mL}$ aliquot of $1,000 \mathrm{ng} / \mathrm{mL}$ ISTD-dibutyl phthalate solution was added to each diluted pyrethroid stock solution using a micro syringe. All stock solutions were stored in a freezer at $-20^{\circ} \mathrm{C}$. Standard solutions were analyzed immediately after preparation followed by sample analysis.

The sample $(20 \mathrm{~mL})$ was transferred into Quechers $15 \mathrm{ml}$ centrifuge tube, then $3 \mathrm{~mL}$ of acetone was added and vortexed (30 sec), sonicated (30 min), shake (15 min, $300 \mathrm{rpm}$ ), centrifuged (15 min, 600 rpm) and transferred into $15 \mathrm{~mL}$ glass conic centrifuge tubes. This procedure was repeated two more times, sonicating 15- and 5 min, respectively. Then collected sample solution in glass conic centrifuge tube was concentrated to $0.5 \mathrm{~mL}$. The concentrated solution was transferred into $1 \mathrm{~mL}$ volumetric flask through $0.5 \mathrm{mg}$ cotton placed in the 5.75-inch Pasteur pipets to the volumetric flask and acetone was added until the final volume reached $1 \mathrm{~mL}$. Then 


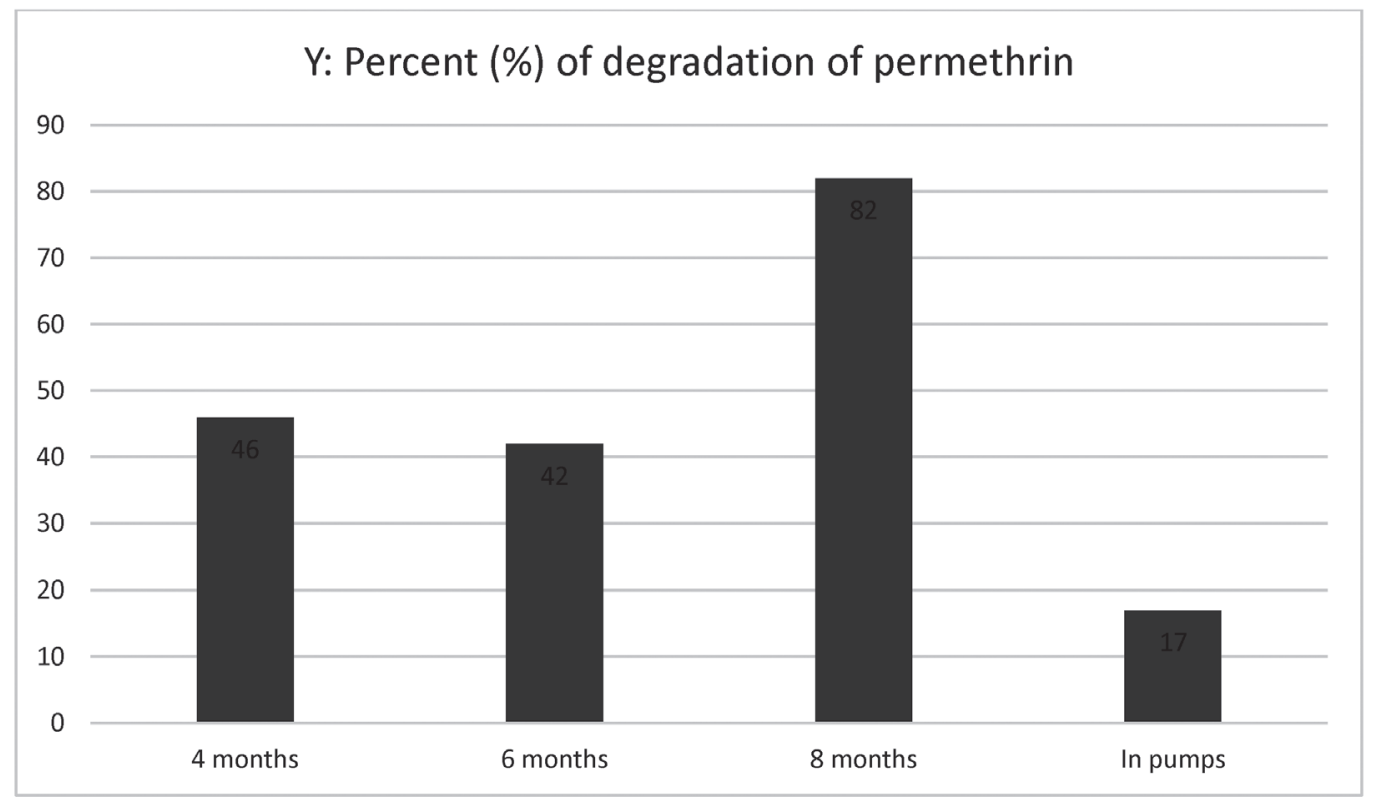

Figure 1. Store time (in months) of Aqualuer 20-20 (a.i. 20.6\% permethrin) and degradations (in \%) of permethrin concentrations in truck-mounted ULV spray tanks after mixed with water for different months, compared with concentrations in stock Aqualuer 20-20 container (as zero degradation).

$5 \mathrm{~mL}$ solution from the volumetric flask was transferred into GC/MS amber vial 10 $\mathrm{mL}$ of ISTD solution $(1,000 \mathrm{ng} / \mathrm{mL})$ and, then acetone was added until the final volume reached $1 \mathrm{~mL}$. This procedure was performed for all 21 samples. Samples were then subjected to the GC-MS analysis immediately after preparation.

A $1 \mu \mathrm{L}$ aliquot from each extract was analyzed along with the appropriate solvent blanks using a Thermo Finnigan DSQ (Thermo Fisher Scientific; Austin, TX, USA) equipped with a DB-5 (Agilent; Santa Clara, CA, USA) column $(30 \mathrm{~m} \times 0.25 \mathrm{~mm}$ inner diameter and $0.25 \mu \mathrm{m}$ the film thickness). The GC oven temperature program was set at $100{ }^{\circ} \mathrm{C}$ as initial temperature, then a ramp at $16{ }^{\circ} \mathrm{C} / \min$ to $200{ }^{\circ} \mathrm{C}$, and at $7{ }^{\circ} \mathrm{C} /$ min to $300{ }^{\circ} \mathrm{C}$ followed by a final hold for $5 \mathrm{~min}$ at $300{ }^{\circ} \mathrm{C}$. The PTV injection port was held at $50{ }^{\circ} \mathrm{C}$ and ramped to $240{ }^{\circ} \mathrm{C}$ in split less mode, the transfer line was set to $240{ }^{\circ} \mathrm{C}$, and the carrier gas was set to a constant flow of $1.2 \mathrm{~mL} / \mathrm{min}$. Analytical mode was set on Selected Ion Monitoring (SIM). The ions selected for SIM quantification of the permethrin were 163 and 183.
During the validation of the analytical method, linear range, limit of detection (LOD), limit of quantification (LOQ), and precision were determined. Linearity was evaluated with 5-point linear plot (three replicates), based on linear regression and squared correlation coefficient $\mathrm{R}^{2}>0.990$. Standards were prepared by spiking a blank with permethrin and then subjecting to the same treatment, as samples. Precision of method was expressed as standard deviation (SD) (three replicates). Precision of the instrument was expressed as the repeatability of the measurements (SD, 6 replicates at concentrations 50, 100 and $250 \mathrm{~m} / \mathrm{L})$. LOD and LOQ were calculated based on the noise level in the chromatograms at $\mathrm{S} / \mathrm{N}$ of $3: 1$ and 10:1 correspondingly. Each sample identification number with store time in months was sorted to a group of 4 months, 6 months, and 8 months. The permethrin degradation (\%) in concentration of each sample was calibrated by using the concentration $(\mathrm{X})$ in stock container minus the concentration $(\mathrm{Y})$ in sample $(\mathrm{X}-\mathrm{Y})$ divide the concentration in stock $(\mathrm{X})$, then multiple $100 \%$. A one-way ANOVA was performed for the data analysis for the percentage of degra- 
dation of permethrin through JMP 13.10 (SAS Institute, Inc. Cary, NC).

A total of 21 truck-mounted ULV spray tanks, one mixing pump, and one stock container were sampled and analyzed by gas chromatography using the methods described above. Two of the 21 samples from truck spray tanks showed $0 \%$ permethrin after analysis. These trucks were designated for fogging only at night and early morning. This result was probably caused by a malfunction with the mixing pump when adding the insecticide or other unknown reasons. Two dual duty trucks (larviciding and adulticiding operated at daytime and nighttime) showed 93\%-98\% permethrin degradation. This may be a result of exposure to sunlight and heat during the daytime outdoor use (Amoo et al 2008). All other samples showed significantly $(F=25,255, \mathrm{P}<0.01)$ different concentrations of permethrin. Figure 1 shows that $17 \%$ degradation in mixing pump with water, and the average of $46 \%, 42 \%$, and $82 \%$ degradation of permethrin in concentrations stored in ULV spray tanks for 4,6 , and 8 months, during the mosquito off season, compared with the concentrations sampled from the stock container. The percent degradation between 4 months (46\%) and 6 months (42\%) did not show any significant differences. The permethrin concentration after storage for 8 months or more demonstrated ( $F=23,407$, $\mathrm{P}$ $<0.01)$ the highest degradation after mixing with water.
In conclusion, the longer the storage time (in months) of permethrin (after being mixed with water during the mosquito off season) in truck-mounted ULV spray tanks, the more degraded it became. For the improvement of operational control effectiveness, the concentrations of permethrin in spray tanks, if stored over the mosquito off season, should be analyzed before conducting ULV spray and after the product has been mixed with water for several months. If low concentrations of the active ingredient permethrin are detected, additional permethrin should be added from the stock container. Also, emptying spray tanks after the mosquito season or adding new mixed permethrin into the spray tank before conducting ULV spray is recommended.

\section{REFERENCES CITED}

Amoo AO, Xue RD, Qualls WA, Quinn BP, Bernier UR. 2008. Residual efficacy of field-applied permethrin, d-phenothrin, and resmethrin on plant foliage against adult mosquitoes. J. Am. Mosq. Control Assoc. 24:543-549.

Amoo AO, Xue RD, Qualls WA, Wang ZM, Zhao TY. 2012. Efficacy evaluation of three permethrin products against caged Culex quinquefasciatus. Acta Parasitol Med. Entomol. Sinica 19:19-24.

Brown JR, Xue, RD. 2011. Ground application of Aquareslin and Aquakontrol against Anopheles quadrimaculatus, Aedes aegypti, and Aedes albopictus, J. Am. Mosq. Control Assoc. 27:330-332.

Xue RD, Qualls WA, Zhong H, Brock CL. 2008. Permethrin decomposition after four month storage in the spray truck tanks during mosquito-off season. J. Am. Mosq. Control Assoc. 24:127-129. 